Zuzana Walker, MD

Emilio Moreno, MD

Alan Thomas, MD

Fraser Inglis, MD

Naji Tabet, MD

Tim Stevens, MD

Tim Whitfield, MSc

Dag Aarsland, MD

Michael Rainer, MD

Alessandro Padovani, MD

On behalf of the

DaTSCAN DLB Phase

4 Study Group

Correspondence to

Dr. Walker:

z.walker@ucl.ac.uk

Supplemental data at Neurology.org

\title{
Evolution of clinical features in possible DLB depending on FP-CIT SPECT result OPEN
}

\section{ABSTRACT}

Objective: To test the hypothesis that core and suggestive features in possible dementia with Lewy bodies (DLB) would vary in their ability to predict an abnormal dopamine transporter scan and therefore a follow-up diagnosis of probable DLB. A further objective was to assess the evolution of core and suggestive features in patients with possible DLB over time depending on the 123/-FP-CIT SPECT scan result.

Methods: A total of 187 patients with possible DLB (dementia plus one core or one suggestive feature) were randomized to have dopamine transporter imaging or to follow-up without scan. DLB features were compared at baseline and at 6-month follow-up according to imaging results and follow-up diagnosis.

Results: For the whole cohort, the baseline frequency of parkinsonism was 30\%, fluctuations 29\%, visual hallucinations 24\%, and REM sleep behavior disorder 17\%. Clinician-rated presence of parkinsonism at baseline was significantly ( $p=0.001)$ more frequent and Unified Parkinson's Disease Rating Scale (UPDRS) score at baseline was significantly higher $(p=0.02)$ in patients with abnormal imaging. There was a significant increase in UPDRS score in the abnormal scan group over time $(p<0.01)$. There was relatively little evolution of the rest of the DLB features regardless of the imaging result.

Conclusions: In patients with possible DLB, apart from UPDRS score, there was no difference in the evolution of DLB clinical features over 6 months between cases with normal and abnormal imaging. Only parkinsonism and dopamine transporter imaging helped to differentiate DLB from non-DLB dementia. Neurology ${ }^{\circledR}$ 2016;87:1045-1051

\section{GLOSSARY}

DLB = dementia with Lewy bodies; GDS = Geriatric Depression Scale; MMSE = Mini-Mental State Examination; MTA = medial temporal atrophy; $\mathbf{M T L}=$ medial temporal lobes; RBD = REM sleep behavior disorder; UPDRS = Unified Parkinson's Disease Rating Scale.

The diagnosis of dementia with Lewy bodies (DLB) continues to be challenging. At present, the clinical diagnosis of DLB is based on a set of criteria proposed by the DLB Consortium ${ }^{1}$ that establish different levels of certainty (possible DLB and probable DLB). Patients with possible DLB have a particularly uncertain diagnosis with the follow-up diagnosis being equally likely to be probable DLB or non-DLB dementia. ${ }^{2}$

Accurate clinical diagnosis is relevant for the appropriate management of patients with DLB as they require a different approach by comparison with non-DLB dementia for the control of their parkinsonian features, psychotic symptoms, sleep disorders, and autonomic dysfunction. ${ }^{3}$

In most degenerative disorders, the diagnosis becomes more certain with time, as the symptoms evolve. However, in a recent study, ${ }^{4}$ the diagnosis became more certain in only $16 \%$ of

\footnotetext{
From University College London (Z.W.); North Essex Partnership University NHS Foundation Trust (Z.W., T.S., T.W.), Braintree; GE Healthcare (E.M.), Buckinghamshire; Newcastle University (A.T.), Newcastle upon Tyne; Glasgow Memory Clinic Ltd. (F.I.); Brighton and Sussex Medical School (N.T.), Brighton, UK; Centre for Age-Related Diseases (D.A.), Stavanger University Hospital; Department of Geriatric Psychiatry (D.A.), Akershus University Hospital, Oslo, Norway; Department of Neurobiology, (D.A.) Care Sciences and Society Division of Alzheimer's Disease Research Centre, Karolinska Institutet, Stockholm, Sweden; Karl Landsteiner Institut für Gedächtnis und Alzheimerforschung Wien (M.R.), Austria; and University of Brescia (A.P.), Italy.

Coinvestigators are listed at Neurology.org.

Go to Neurology.org for full disclosures. Funding information and disclosures deemed relevant by the authors, if any, are provided at the end of the article. The Article Processing Charge was paid by GE Healthcare.

This is an open access article distributed under the terms of the Creative Commons Attribution-NonCommercial-NoDerivatives License 4.0 (CC BY-NC-ND), which permits downloading and sharing the work provided it is properly cited. The work cannot be changed in any way or used commercially.
} 
possible DLB cases at 6 months follow-up without the aid of dopamine transporter imaging. No large prospective study of possible DLB cases has specifically examined the evolution of DLB features and their association with dopamine transporter imaging result and follow-up diagnosis. Dopamine transporter loss has been shown reliably to differentiate DLB from other dementias ${ }^{5}$ and is increasingly used as an imaging biomarker for the diagnosis of probable DLB. This exploratory study tested the hypothesis that individual core and suggestive features would vary in their ability to predict an abnormal scan. A further objective was to study the evolution of the core, suggestive, and supportive features over time according to the scan result.

METHODS Study design and participants. The methods have been described in detail elsewhere. ${ }^{4}$ In brief, data were collected as part of a multicenter, randomized, open-label phase IV trial in 21 centers in 6 European countries. ${ }^{4}$ The study took place between January 14, 2011, and October 8, 2012. Patients had to be at least 55 years old and have a Mini-Mental State Examination (MMSE) ${ }^{6}$ score between 10 and $28 .{ }^{4}$ Patients were diagnosed by local clinicians as having possible DLB according to the Consensus criteria. ${ }^{1}$ All patients had to have a reliable informant who also consented to take part.

Standard protocol approvals, registrations, and patient consents. This study was approved by the NRES Committee London-Central and informed written consent was obtained from each patient and his or her informant. The study complied with the Good Clinical Practice: Consolidated Guideline approved by the International Conference on Harmonisation, the Declaration of Helsinki, and any relevant national and local laws and regulations. ${ }^{4}$

Trial registration. The data were generated from a trial registered under EudraCT number 2010-021474-11, and the results of the study have been submitted to the EudraCT Web page.

Procedures. Patients who did not have an MRI scan performed before the baseline had a standard MRI scan unless contraindicated. ${ }^{4}$ Physicians reviewed MRI/CT and dichotomized images into medial temporal atrophy (MTA) being present or not present.

At baseline, the following information was collected for all participants: demographic details, medical and surgical history, concomitant medication, physical examination, Unified Parkinson's Disease Rating Scale (UPDRS)-III score (there was no requirement to stop antiparkinsonian medication if on treatment), Addenbrooke's Cognitive Examination-Revised, ${ }^{7}$ Neuropsychiatric inventory, ${ }^{8}$ Clinician Assessment of Fluctuation Scale, ${ }^{9}$ and Geriatric Depression Scale (GDS). ${ }^{10}$ Local investigators decided on the presence of core and suggestive DLB features according to Consensus criteria ${ }^{1}$ and assigned the appropriate dementia diagnostic category. ${ }^{4}$ Investigators rated REM sleep behavior disorder (RBD) according to local clinical practice.

Following baseline visit, participants were randomised to undergo a ${ }^{123}$ I-FP-CIT SPECT scan or no imaging at a ratio of
2:1. Participants and research staff were aware of patients' randomization status. ${ }^{4}$ Patients in the control group were also offered a ${ }^{123}$ I-FP-CIT SPECT examination at the end of the study, although the results of those scans did not inform the present analysis.

SPECT imaging. Each patient received an IV injection with 111-185 MBq of ${ }^{123}$ I-FP-CIT and 3-6 hours later had a SPECT scan to determine the functional integrity of the nigrostriatal dopaminergic neuron terminals in the striatum. Thyroid blocking was performed according to protocol. ${ }^{4}$

Images were visually rated by local nuclear medicine specialists and assigned to category: normal (normal uptake across all regions) or abnormal type 1 (asymmetric activity with reduced uptake in one putamen), type 2 (absent activity in putamen bilaterally), type 3 (absent activity in putamen bilaterally and significantly reduced in one or both caudate nuclei), or type 4 (other abnormal pattern). The type 4 rating was given when no clear pattern could be determined but the scan was clearly abnormal. The nuclear medicine specialists were blinded to all clinical data. ${ }^{4}$

Participants in both arms were assessed $8( \pm 1)$ weeks after baseline and had a repeat physical examination and UPDRS-III score. Clinicians again recorded DLB features and assigned a dementia diagnostic category. Further reassessment took place $24( \pm 2)$ weeks after baseline and baseline schedules were repeated. ${ }^{4}$ For patients in the imaging group, ${ }^{123}$ I-FP-CIT scan results were available to the local clinicians both at weeks 8 and 24 .

Statistical analysis. A comparison was made between symptoms at baseline compared to symptoms at 8 and 24 weeks within imaging groups and diagnostic groups. The percentage of abnormal scans for the different subgroups according to the features present at baseline was calculated. Fisher exact tests were used to compare the proportion of abnormal:normal scan in participants with a particular DLB feature. Cochran-Armitage tests were used to evaluate the significance of evolution of categorically defined symptoms over time. An analysis of covariance model with ${ }^{123}$ I-FP-CIT scan result (normal or abnormal) as the main effect and baseline value as a covariate was used to assess evolution of continuously measured variables (e.g., UPDRS score). Core and suggestive features were tested for their ability to predict scan result using logistic regression.

RESULTS Of the 170 participants, 114 had a ${ }^{123} \mathrm{I}-$ FP-CIT scan and 56 did not have a scan (controls). Of the 114 imaged patients, $43 \%$ had an abnormal scan. As reported previously, ${ }^{4}$ at both 8 and 24 weeks, significantly more patients in the imaging group had a change in diagnosis from baseline compared to controls $(61 \%$ vs $4 \%$ and $71 \%$ vs $16 \%$; both $p<$ $0.0001)$. If the scan was abnormal, clinicians were more likely to change the diagnosis (82\%) compared to when the scan was normal (46\%). At 24 weeks, $81 \%$ of patients with an abnormal scan had a clinical diagnosis of probable DLB.

Baseline demographics. Baseline demographics for the whole group and for the imaging and control groups separately are shown in table 1 .

Baseline and 24-week follow-up. Five participants were excluded from the analysis due to inappropriate study entry. Frequency of DLB features for the remaining 
Table 1 Baseline demographics and schedules

\begin{tabular}{|c|c|c|c|}
\hline & $\begin{array}{l}\text { Total group } \\
(\mathrm{n}=170)\end{array}$ & $\begin{array}{l}\text { Imaging } \\
\text { group } \\
(\mathrm{n}=114)\end{array}$ & $\begin{array}{l}\text { Control } \\
\text { group } \\
(n=56)\end{array}$ \\
\hline \multicolumn{4}{|l|}{ Sex, n (\%) } \\
\hline Male & 93 (54.7) & $64(56.1)$ & 29 (51.8) \\
\hline Female & $77(45.3)$ & 50 (43.9) & 27 (48.2) \\
\hline \multicolumn{4}{|l|}{ Age, $y$} \\
\hline Mean (SD) & $75.0(7.25)$ & $75.2(7.08)$ & $74.6(7.63)$ \\
\hline \multicolumn{4}{|l|}{ Geriatric Depression Scale $(0-15)^{a}$} \\
\hline Mean (SD) & $3.5(2.76)^{b}$ & $3.3(2.91)^{b}$ & $3.8(2.43)$ \\
\hline Median (IQ range) & $3(2-5)$ & $3(1-5)$ & $3(2-6)$ \\
\hline \multicolumn{4}{|l|}{ Fluctuation scale $(0-16)^{a}$} \\
\hline Mean (SD) & 2.5 (3.72) & $2.9(3.76)$ & $1.9(3.57)$ \\
\hline Median (IQ range) & $0(0-6)$ & $0(0-6)$ & $0(0-2.5)$ \\
\hline No. (\%) with Fluctuation scale $>0$ & 67 (39) & $51(45)$ & $16(29)$ \\
\hline \multicolumn{4}{|l|}{ ACE-R $(0-100)^{a}$} \\
\hline Mean (SD) & $62.5(17.0)$ & $63.8(17.1)$ & $59.8(16.6)$ \\
\hline Median (IQ range) & $62.5(50-77)$ & $63.5(52-78)$ & $56.0(50-74)$ \\
\hline \multicolumn{4}{|l|}{ MMSE (0-30) } \\
\hline Mean (SD) & $22.1(4.66)$ & $22.2(4.67)$ & $21.9(4.69)$ \\
\hline Median (IQ range) & $23(19-26)$ & $23(20-26)$ & $22(19-26)$ \\
\hline \multicolumn{4}{|l|}{ NPI total $(0-144)^{a}$} \\
\hline Mean (SD) & $15.0(14.75)^{b}$ & $15.9(14.66)$ & $13.3(14.93)^{\mathrm{b}}$ \\
\hline Median (IQ range) & $12(4-21)$ & $13(5-23)$ & $10(4-18)$ \\
\hline \multicolumn{4}{|l|}{ NPI caregiver distress $(0-60)^{a}$} \\
\hline Mean (SD) & $8.1(7.73)^{b}$ & $8.6(8.17)$ & $7.1(6.72)^{b}$ \\
\hline Median (IQ range) & $6(2-11)$ & $6(2-13)$ & $7(2-10)$ \\
\hline \multicolumn{4}{|c|}{ UPDRS part III overall assessment $(0-56)^{a}$} \\
\hline Mean (SD) & $9.3(8.15)$ & $9.3(8.47)$ & $9.2(7.53)$ \\
\hline Median (IQ range) & $7(2-15)$ & $6.5(2-15)$ & $8.0(2-15)$ \\
\hline
\end{tabular}

Abbreviations: ACE-R = Addenbrooke's Cognitive Examination-Revised; MMSE $=$ MiniMental State Examination; NPI = neuropsychiatric inventory; UPDRS = Unified Parkinson's Disease Rating Scale.

${ }^{a}$ Data in parentheses represent theoretical range values for the test.

${ }^{\mathrm{b}}$ Data for one patient were missing.

165 participants and for the imaging and control groups are listed in table 2 .

DLB features according to scan result. The presence of characteristic features of DLB and the result of the ${ }^{123}$ I-FP-CIT scan are shown in figure 1. Significantly more patients with parkinsonian features had an abnormal scan $(70 \%)$ compared to other features, where $32 \%-37 \%$ had an abnormal scan $(p=0.001)$.

Prediction of scan result by baseline features of DLB. When analyzing the results using a number of different models, which included entering fluctuations, visual hallucinations, parkinsonism, and RBD each separately, or parkinsonism in combination with the other variables, only parkinsonism was a significant predictor of an abnormal scan result ( $p=0.003)$.

Higher total score on UPDRS was associated with an abnormal scan $(p=0.02)$. Facial expression and bradykinesia were the only subcomponents of the UPDRS to be significantly associated with an abnormal scan (both $p<0.0001$ ).

Of the patients who had an abnormal scan, significantly more patients had preserved medial temporal lobes (MTL) (57\%; $p=0.001$; Fisher exact test), a supportive feature of DLB, compared to patients with a normal scan, where only $26 \%$ had preserved MTL (figure 2). There was no significant difference in any of the other supportive features in patients with an abnormal ${ }^{123}$ I-FP-CIT scan.

There was no difference in the frequency of depression between the normal scan and abnormal scan groups $(p=0.1)$. The mean GDS score in the abnormal scan group $(3.5 \pm 2.9)$ compared to the normal scan group (3.2 \pm 2.9$)$ was not significantly different.

Evolution of symptoms according to scan result. In participants with abnormal scans, the frequency of all features stayed stable over 6 months, apart from parkinsonism, which increased, though this did not reach statistical significance (figure 3). However, there was a significant increase in UPDRS score at 24 weeks $(p<0.01)$ compared to baseline in patients with an abnormal scan. The frequency of DLB features in participants with normal scans was unchanged over time except for visual hallucinations, which decreased from $26 \%$ to $10 \%(p=0.04)$. In patients with hallucinations at baseline, there was no difference between the groups with abnormal and normal scan in initiation or increase of medication during follow-up (cholinesterase inhibitor, memantine, or antipsychotic). In the abnormal group, $6 / 8$ patients were started on a cholinesterase inhibitor or had their dose increased. In the normal group, 8/14 patients with a normal scan were started on a cholinesterase inhibitor $(\mathrm{n}=5)$ or memantine $(\mathrm{n}=3)$ or had their dose increased. No patient in either group was started on an antipsychotic or had the dose increased.

Evolution of features according to final diagnosis. The only feature that increased in frequency in patients with a follow-up diagnosis of probable DLB was parkinsonism, although this did not reach statistical significance. The frequency of fluctuations decreased in patients with a final diagnosis of non-DLB dementia $(p=0.03)$. The evolution of all DLB core and suggestive features according to follow-up diagnosis is shown in figure e-1 at Neurology.org.

DISCUSSION In this large prospective cohort of patients with possible DLB, parkinsonism was the only feature that predicted an abnormal ${ }^{123}$ I-FP-CIT scan. 


\begin{tabular}{|c|c|c|c|c|}
\hline Table 2 & \multicolumn{4}{|c|}{$\begin{array}{l}\text { Presence of core and suggestive dementia with Lewy bodies (DLB) } \\
\text { features at baseline and } 24 \text {-week follow-up, } n(\%)\end{array}$} \\
\hline DLB feature & type & Total group & Imaging group & Control group \\
\hline \multicolumn{5}{|l|}{ No. } \\
\hline Baseline & & 165 & 111 & 54 \\
\hline Follow-up & & 159 & 106 & 53 \\
\hline \multicolumn{5}{|c|}{ Fluctuating cognition, $\mathrm{n}(\%)$} \\
\hline Baseline & & $48(29)$ & 35 (31) & $13(24)$ \\
\hline Follow-up & & $40(25)$ & $30(28)$ & $10(20)$ \\
\hline \multicolumn{5}{|c|}{ Visual hallucinations, n (\%) } \\
\hline Baseline & & $40(24)$ & 24 (22) & $16(30)$ \\
\hline Follow-up & & $29(18)$ & $14(13)$ & $15(28)$ \\
\hline \multicolumn{5}{|c|}{ Features of parkinsonism, $n$ (\%) } \\
\hline Baseline & & $49(30)$ & $30(27)$ & 19 (35) \\
\hline Follow-up & & 56 (32) & 34 (32) & $22(41)$ \\
\hline \multicolumn{5}{|c|}{ REM sleep behavior disorders, n (\%) } \\
\hline Baseline & & $28(17)$ & $22(20)$ & $6(11)^{a}$ \\
\hline Follow-up & & $27(17)$ & $21(20)^{a}$ & $6(11)^{b}$ \\
\hline \multicolumn{5}{|c|}{ Severe sensitivity to antipsychotics } \\
\hline Baseline & & 0 & 0 & 0 \\
\hline Follow-up & & 0 & 0 & 0 \\
\hline
\end{tabular}

The results of DLB feature type were classified into 2 groups: present and other (including not present, unclear). Percentages are calculated excluding cases where information was not available (a 1 participant; ${ }^{b} 5$ participants).

Only $27 \%$ of the imaging group had significant parkinsonism as rated by the clinician at baseline but $43 \%$ had an abnormal scan. On the other hand, a third of the patients with parkinsonism had a normal scan, making the diagnosis of DLB less likely. In contrast, a third of patients without parkinsonism but with only hallucinations or fluctuations had an abnormal scan. If we consider an abnormal dopamine transporter scan an indicator of DLB pathology, this highlights the difficulty of making a correct clinical diagnosis in patients with only one feature of DLB and no imaging.

The frequency of the various features of DLB somewhat increased in patients with an abnormal scan or probable DLB diagnosis at 6 months. However, the changes were not particularly striking. This is surprising, as both visual hallucinations ${ }^{11}$ and the presence of $\mathrm{RBD}^{12}$ are reported to be good predictors of future DLB diagnosis in the prodromal and early stages of the disease. It is of note that even in the normal scan group, some patients still had fluctuating cognition, visual hallucinations, or parkinsonism at 24 weeks followup. The explanation could be that some patients with $\mathrm{AD}$ and a normal scan have some DLB features. It has been shown that all DLB features can be present in a minority of $\mathrm{AD}$ cases. ${ }^{13} \mathrm{An}$ alternative, applicable to those with persistent fluctuating cognition or visual hallucinations, is that the patients did have cortical Lewy body pathology with no involvement of the striatum and therefore a normal scan. ${ }^{14}$

Some patients had an abnormal scan without any parkinsonian features. The reason that patients with abnormal imaging do not have parkinsonism is most likely due to the dopaminergic deficit not being severe enough to cause clinical features. ${ }^{15}$ But a third of patients with parkinsonian features had a normal scan. In these cases, there must be an alternative pathologic substrate for the parkinsonism.

In patients with a normal scan, visual hallucinations decreased over time, raising the possibility that

Figure 1 Percentage of abnormal and normal scans for each characteristic feature of dementia with Lewy bodies at baseline

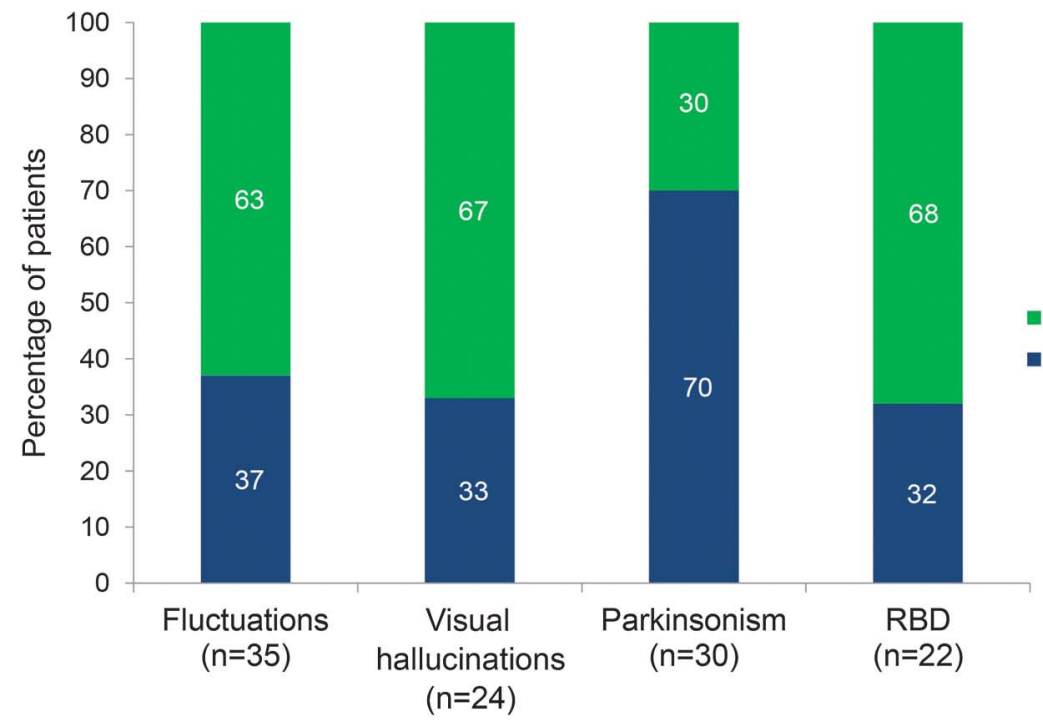

normal scan

- Abnormal scan

$\mathrm{RBD}=\mathrm{REM}$ sleep behavior disorder. Total number of patients with imaging $=111$. 
Figure 2 Baseline imaging results according to supportive dementia with Lewy bodies feature

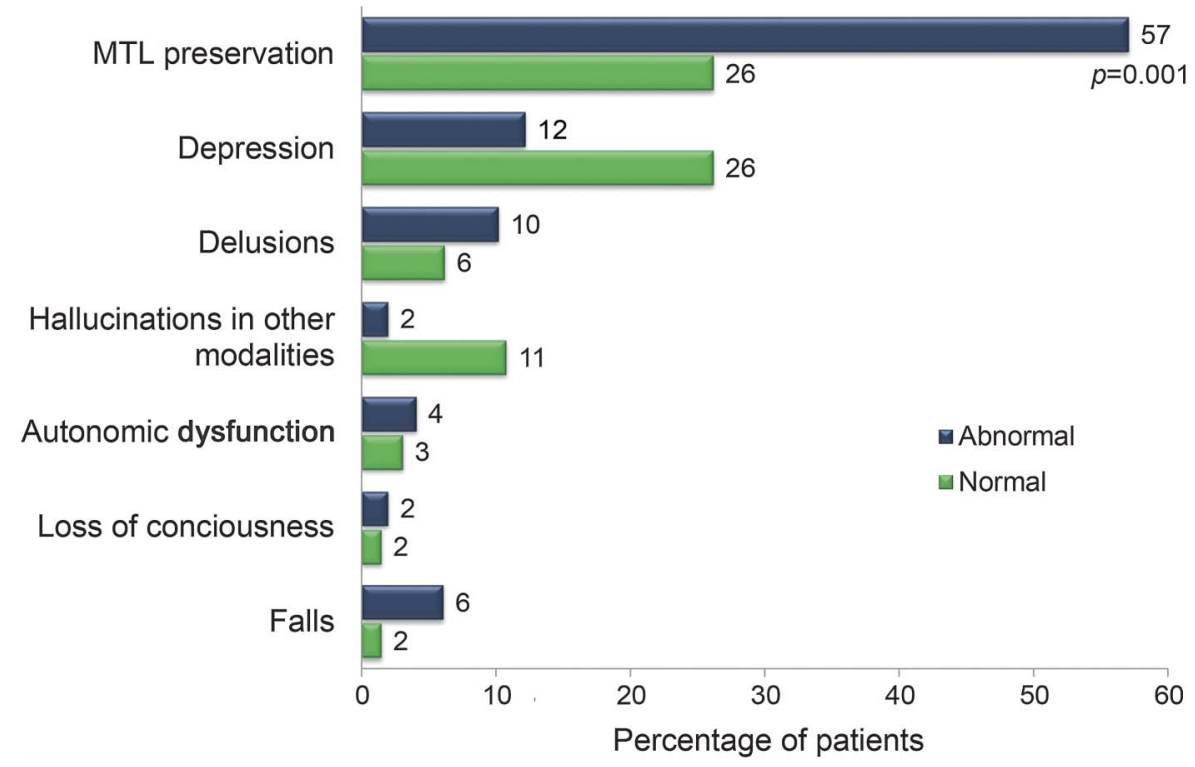

$\mathrm{MTL}=$ medial temporal lobe.

the visual hallucinations were a temporary symptom related to an undiagnosed delirium. Another possibility would be that clinicians were more confident treating visual hallucinations with an antipsychotic in patients with a normal scan. However, this was not the case in our study.

Preservation of MTL was associated with both the diagnosis of probable DLB and an abnormal scan. This is in keeping with a study ${ }^{16}$ that found that MTL atrophy on MRI had good discriminatory power for distinguishing $\mathrm{AD}$ from $\mathrm{DLB}$ and vascular cognitive impairment in pathologically confirmed cases. A more recent study, again with autopsyconfirmed cases, showed that DLB patients without significant $\mathrm{AD}$ pathology had reduced global and regional atrophy. ${ }^{17}$ However, patients with mixed DLB/AD pathology had greater atrophy, on a par with patients with $\mathrm{AD}$. This would suggest that, in a clinical setting, the combination of an abnormal ${ }^{123}$ I-FP-CIT scan and preserved MTL is indicative of predominantly DLB pathology. Surprisingly, patients with abnormal scans had a lower frequency of depression. However, as expected, the mean GDS score was higher in the abnormal scan group.

Figure $3 \quad$ Evolution of dementia with Lewy bodies features by imaging results

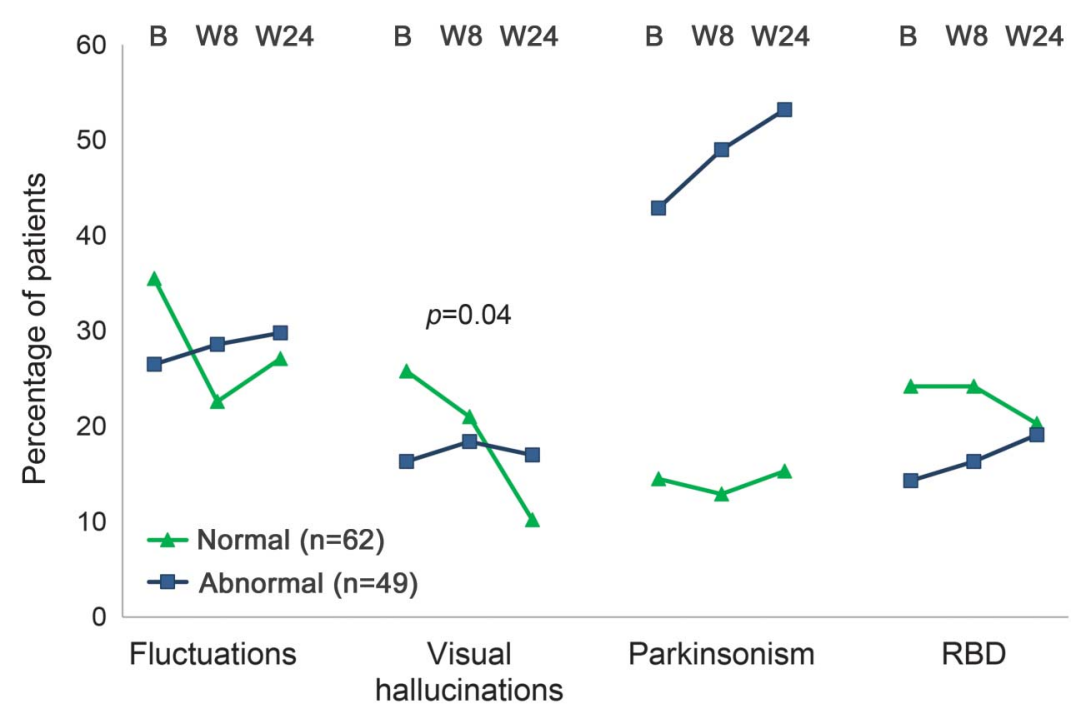

$\mathrm{B}=$ baseline; RBD = REM sleep behavior disorder; W8 = week 8; W24 = week 24. The p value is from Cochran-Armitage test. 
The frequency of abnormal ${ }^{123}$ I-FP-CIT imaging in possible DLB is in keeping with the phase III study, ${ }^{18}$ where $38 \%$ of cases with possible DLB had positive imaging and explains to some extent why the diagnosis of DLB is so frequently missed.

Although some authors suggest that RBD is an excellent predictor of synucleinopathies, ${ }^{19}$ twothirds of patients with reported RBD had a normal ${ }^{123}$ I-FP-CIT scan. We did not perform polysomnography and the RBD diagnosis was based on an interview with the caregiver. Clinicians were encouraged to use the Mayo Sleep Questionnaire but this was not mandatory. It is therefore possible that the clinicians did not sufficiently separate true RBD from another sleep disorder. As a result, it is difficult to make any definite conclusions with regards to RBD.

This is the largest prospective follow-up of possible DLB cases with dopamine transporter imaging. The sample is fairly representative, as it came from both academic and local clinical centers and involved patients under treatment by both psychiatrists and neurologists. All patients underwent a comprehensive baseline and follow-up assessment. Patients with significant vascular pathology on MRI were excluded. Furthermore, patients with considerable extrapyramidal symptoms (UPDRS-III score above 30) were excluded, so only patients with mild parkinsonism were eligible for the study. Further strengths were that we included a control group and that very few patients were lost to follow-up.

The main limitation of the study is the lack of autopsy confirmation of diagnosis. However, in a study of this size from multiple countries and centers, this would be logistically difficult and take a considerable length of follow-up; the majority of patients were still in the mild to moderate stage of the illness, as indicated by the mean MMSE above 20. Perhaps a longer follow-up would lead to greater evolution of features and enable us to establish which features are most helpful in cases with uncertain diagnosis. Not all features were assessed using standardized assessments but this was also a strength as it better reflected everyday clinical practice. At the time of follow-up, the clinicians were aware of the result of the scan, and this might have made them more alert to parkinsonian features in patients with an abnormal scan. Another limitation was the nonstandardized local review of MTA. The local clinicians/radiologists rated whether MTA was present or absent according to local protocols. No central radiologic assessment was performed.

In patients with possible DLB, apart from parkinsonism as measured by UPDRS, there was no difference in the evolution of DLB clinical symptoms over 6 months between cases with normal and abnormal imaging. Parkinsonism and preserved MTL were associated with abnormal imaging and therefore a greater likelihood of a probable DLB diagnosis. However, a third of cases with parkinsonism did not have abnormal imaging and are therefore less likely to have DLB pathology. In patients with possible DLB, ${ }^{123}$ I-FP-CIT imaging, parkinsonism, and preserved MTL can therefore help to separate patients with and without probable DLB.

\section{AUTHOR CONTRIBUTIONS}

Dr. Walker was involved in the design and conceptualization of the study and interpretation of the data and wrote the first draft of the manuscript and collated and revised further versions of the manuscript, including the final version, for intellectual content. Dr. Moreno was involved in the design and conceptualization of the study, analysis and interpretation of the data, and revised the manuscript for intellectual content and approved the final version. Professor Thomas, Dr. Inglis, Dr. Tabet, Dr. Stevens, Professor Rainer, and Professor Padovani were involved in conceptualizing the study and revised the manuscript for intellectual content and approved the final version. T. Whitfield and Professor Aarsland revised the manuscript for intellectual content and approved the final version.

\section{ACKNOWLEDGMENT}

The statistical analysis plan for this study was formulated by Carol Tseng, $\mathrm{PhD}$ (biostatistician) of $\mathrm{H}_{2} \mathrm{O}$ Clinical LLC. The authors thank the patients and carers for participating in the phase IV study and the support staff at the local nuclear medicine departments for their help.

\section{STUDY FUNDING}

The study was funded by GE Healthcare (GEHC). The study was designed by the Chief Investigator (Z.W.) together with GEHC. In addition to providing funding, GEHC was responsible by itself or under third-party agreement for monitoring, data collection, and statistical analysis under the supervision of the Chief Investigator. All data were available to the Chief Investigator and the authors of the manuscript.

\section{DISCLOSURE}

Z. Walker has received funding for travel, consultancy, and speaker fees and research support from GE Healthcare (GEHC). E. Moreno is a fulltime employee of GEHC. A. Thomas has received research support for an investigator-led study from GEHC. F. Inglis has received speaker fees as a consultant to Pfizer and funding for research work conducted with Abbott Laboratories Ltd., Eli Lilly, GEHC, Genentech, Medivation Inc., Noscira, Pfizer, and Roche. N. Tabet has received speaker fees from Eli Lilly and Pfizer and consultancy fees from GEHC. T. Stevens and T. Whitfield report no disclosures relevant to the manuscript. D. Aarsland reports grants from GEHC, personal fees from Novartis, and personal fees from $\mathrm{H}$ Lundbeck. M. Rainer and A. Padovani report no disclosures relevant to the manuscript. Go to Neurology.org for full disclosures.

Received September 4, 2015. Accepted in final form May 23, 2016.

\section{REFERENCES}

1. McKeith IG, Dickson DW, Lowe J, et al. Diagnosis and management of dementia with Lewy bodies: third report of the DLB consortium. Neurology 2005;65:1863-1872.

2. O'Brien JT, McKeith IG, Walker Z, et al. Diagnostic accuracy of I-123-FP-CIT SPECT in possible dementia with Lewy bodies. Br J Psychiatry 2009;194:34-39.

3. Walker Z, Possin KL, Boeve BF, Aarsland D. Lewy body dementias. Lancet 2015;386:1683-1697.

4. Walker Z, Moreno E, Thomas A, et al. Clinical usefulness of dopamine transporter SPECT imaging with I-123-FPCIT in patients with possible dementia with Lewy bodies: randomised study. Br J Psychiatry 2015;206:145-152. 
5. O'Brien JT, Oertel WH, McKeith IG, et al. Is ioflupane I123 injection diagnostically effective in patients with movement disorders and dementia? Pooled analysis of four clinical trials. BMJ Open 2014;4:e005122.

6. Folstein MF, Folstein SE, Mchugh PR. Mini-mental state: practical method for grading cognitive state of patients for clinician. J Psychiatr Res 1975;12:189-198.

7. Mioshi E, Dawson K, Mitchell J, Arnold R, Hodges JR. The Addenbrooke's Cognitive Examination Revised (ACE-R): a brief cognitive test battery for dementia screening. Int J Geriatr Psychiatry 2006;21:1078-1085.

8. Cummings JL, Mega M, Gray K, Rosenbergthompson S, Carusi DA, Gornbein J. The Neuropsychiatric Inventory: comprehensive assessment of psychopathology in dementia. Neurology 1994;44:2308-2314.

9. Walker MP, Ayre GA, Cummings JL, et al. The clinician assessment of fluctuation and the one day fluctuation assessment scale: two methods to assess fluctuating confusion in dementia. Br J Psychiatry 2000;177:252-256.

10. Sheikh JI, Yesavage JA. Geriatric Depression Scale (GDS): recent evidence and development of a shorter version. In: Brink TL, ed. Clinical Gerontology: A Guide to Assessment and Intervention. New York: The Haworth Press; 1986:165-173.

11. Tiraboschi P, Salmon DP, Hansen LA, Hofstetter RC, Thal LJ, Corey-Bloom J. What best differentiates Lewy body from Alzheimer's disease in early-stage dementia? Brain 2006;129:729-735.

12. Schenck CH, Boeve BF, Mahowald MW. Delayed emergence of a parkinsonian disorder or dementia in $81 \%$ of older men initially diagnosed with idiopathic rapid eye movement sleep behavior disorder: a 16-year update on a previously reported series. Sleep Med 2013;14:744-748.

13. McKeith IG. Dementia with Lewy bodies. Br J Psychiatry 2002;180:144-147.

14. Colloby SJ, McParland S, O’Brien JT, Attems J. Neuropathological correlates of dopaminergic imaging in Alzheimer's disease and Lewy body dementias. Brain 2012;135: 2798-2808.

15. Filippi L, Manni C, Pierantozzi M, et al. I-123-FP-CIT semi-quantitative SPECT detects preclinical bilateral dopaminergic deficit in early Parkinson's disease with unilateral symptoms. Nucl Med Commun 2005;26: 421-426.

16. Burton EJ, Barber R, Mukaetova-Ladinska EB, et al. Medial temporal lobe atrophy on MRI differentiates Alzheimers disease from dementia with Lewy bodies and vascular cognitive impairment: a prospective study with pathological verification of diagnosis. Brain 2009;132: 195-203.

17. Nedelska Z, Ferman TJ, Boeve BF, et al. Pattern of brain atrophy rates in autopsy-confirmed dementia with Lewy bodies. Neurobiol Aging 2015;36:452-461.

18. McKeith I, O'Brien J, Walker Z, et al. Sensitivity and specificity of dopamine transporter imaging with (123)IFP-CIT SPECT in dementia with Lewy bodies: a phase III, multicentre study. Lancet Neurol 2007;6:305-313.

19. Pao WC, Boeve BF, Ferman TJ, et al. Polysomnographic findings in dementia with Lewy bodies. Neurologist 2013; 19:1-6.

\section{Enjoy Neurology ${ }^{\circledR}$ Clinical Practice on your iPad ${ }^{\circledR}$}

The same information so critical to your practice is now brought to you on the $\mathrm{iPad}^{\circledR}$. This dynamic app optimizes the best in digital technology to enhance the reading experience with article-sharing features, multimedia, links, and more.

\section{Enjoy the benefits:}

- Easy-to-read articles you can share via email and social media

- Adjustable text sizing with "pinch and zoom" technology

- Engaging multimedia videos, images, and data supplements

- Ability to store downloaded issues

- Convenient notification when a new issue is available

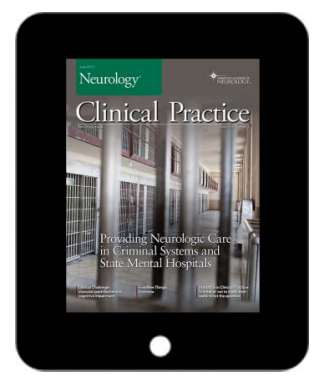

AAN members - enjoy Full Access to every issue on your $\mathrm{iPad}^{\circledR}$. If you are not yet a member, download the app and GET THE LATEST ISSUE FREE! (Go to http://bit.ly/NCPapp for details.) 


\section{Neurology}

Evolution of clinical features in possible DLB depending on FP-CIT SPECT result Zuzana Walker, Emilio Moreno, Alan Thomas, et al.

Neurology 2016;87;1045-1051 Published Online before print August 10, 2016

DOI 10.1212/WNL.0000000000003076

This information is current as of August 10, 2016

\section{Updated Information \& Services}

Supplementary Material

\section{References}

\section{Subspecialty Collections}

Permissions \& Licensing

\section{Reprints}

including high resolution figures, can be found at: http://n.neurology.org/content/87/10/1045.full

Supplementary material can be found at: http://n.neurology.org/content/suppl/2016/08/10/WNL.0000000000003 076.DC2

http://n.neurology.org/content/suppl/2016/08/10/WNL.0000000000003 076.DC1

http://n.neurology.org/content/suppl/2016/09/01/WNL.0000000000003 076.DC3

This article cites 18 articles, 7 of which you can access for free at: http://n.neurology.org/content/87/10/1045.full\#ref-list-1

This article, along with others on similar topics, appears in the following collection(s):

Cohort studies

http://n.neurology.org/cgi/collection/cohort_studies

Dementia with Lewy bodies

http://n.neurology.org/cgi/collection/dementia_with_lewy_bodies SPECT

http://n.neurology.org/cgi/collection/spect

Information about reproducing this article in parts (figures,tables) or in its entirety can be found online at:

http://www.neurology.org/about/about_the_journal\#permissions

Information about ordering reprints can be found online:

http://n.neurology.org/subscribers/advertise

Neurology ${ }^{\circledR}$ is the official journal of the American Academy of Neurology. Published continuously since 1951, it is now a weekly with 48 issues per year. Copyright () 2016 American Academy of Neurology. All rights reserved. Print ISSN: 0028-3878. Online ISSN: 1526-632X.

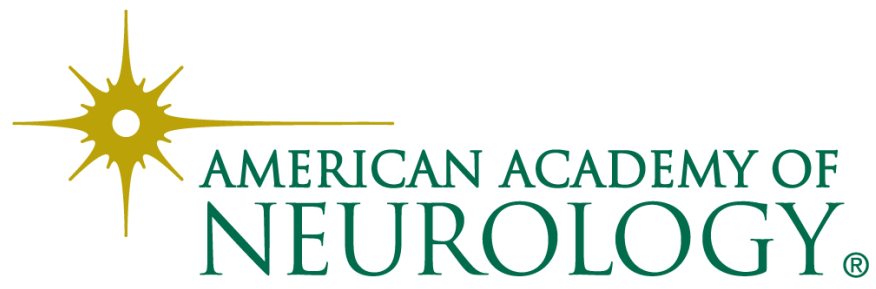

